\title{
The angiotensin-converting enzyme insertion/deletion polymorphism modifies the clinical outcome in patients with Pompe disease
}

\author{
Paola de Filippi, PhD ${ }^{I}$, Sabrina Ravaglia, $M D, P h D^{2}$, Bruno Bembi, $M D^{3}$, Alfredo Costa, $M D^{2}$, \\ Arrigo Moglia, $M D^{2}$, Giovanni Piccolo, $M D^{2}$, Alessandra Repetto, $M D^{2}$, Andrea Dardis, $M D^{3}$, \\ Giuseppe Greco, $M D^{4}$, Giovanni Ciana, $M D^{3}$, Francesco Canevari, PhD ${ }^{1}$, and Cesare Danesino, $M D^{1,5}$
}

\begin{abstract}
Purpose: The insertion/deletion polymorphism of angiotensin-converting enzyme may influence muscle properties. We examined whether Pompe disease clinical manifestations, which are known to be highly variable among late-onset patients, may be modulated by angiotensinconverting enzyme polymorphism. Methods: We included 38 patients with late-onset Pompe disease, aged $44.6 \pm 19.8$ years. We compared the distribution of angiotensin-converting enzyme polymorphism according to demographic and disease parameters. Results: The distribution of angiotensin-converting enzyme polymorphism was in line with the general population, with $16 \%$ of patients carrying the II genotype, $37 \%$ carrying the DD genotype, and the remaining patients with the ID genotype. The three groups did not differ in mean age, disease duration, Walton score, and other scores used to measure disease severity. The DD polymorphism was associated with earlier onset of disease $(P=$ $0.041)$, higher creatine kinase levels at diagnosis $(P=0.024)$, presence of muscle pain $(P=0.014)$, and more severe rate of disease progression ( $P=0.037$, analysis of variance test for interaction). Discussion: These findings suggest a potential role of angiotensin-converting enzyme polymorphism in modulating Pompe disease phenotype and prognosis. Genet Med 2010:12(4):206-211.
\end{abstract}

Key Words: Pompe disease, type II glycogenosis; ACE polymorphism, genotype-phenotype correlation, muscle properties

C lycogen storage disease (GSD) type II or Pompe disease (MIM 232300) is a lysosomal storage disorder caused by mutations in the acid alpha-glucosidase (GAA) gene. A comprehensive review of clinical and genetic data has been recently published. ${ }^{1}$ About 200 different mutations have been described, ${ }^{2}$ but genotype-phenotype correlations are not well established. Patients sharing the same haplotype may indeed experience the first symptoms at different ages, suggesting that other (genetic) factors may consistently influence the clinical outcome of the disease. ${ }^{3,4}$ Clinical heterogeneity is a well

From the ${ }^{1}$ Department of "Patologia Umana ed Ereditaria," University of Pavia, Pavia, Italy; ${ }^{2}$ Department of Neurological Sciences, Institute of Neurology "C. Mondino," University of Pavia, Pavia, Italy; ${ }^{3}$ Regional Center for Rare Disorders, Azienda Ospedaliera Universitaria "Santa Maria della Misericordia," Udine, Italy; ${ }^{4}$ Department of Neurosciences, Neurology Unit, University of Siena, Siena, Italy; and ${ }^{5}$ Medical genetics, "Fondazione IRCCS Policlinico S. Matteo,” Pavia, Italy.

Cesare Danesino, MD, Department of "Patologia Umana ed Ereditaria," Via Forlanini 8, Pavia 27100, Italy. E-mail: cidi@unipv.it.

The first two authors contributed equally to this work.

Disclosure: The authors declare no conflict of interest

Submitted for publication August 16, 2009.

Accepted for publication December 20, 2009.

Published online ahead of print March 19, 2010.

DOI: $10.1097 /$ GIM.0b013e3181d2900e known feature of GSD II, which is more frequently observed among late-onset patients ${ }^{5}$ and is reported even within families. ${ }^{5,6}$ Animal models too show clinical heterogeneity. ${ }^{7}$ In this study, we focused our attention on elucidating whether the well-known insertion/deletion polymorphism in the Intron 16 of the angiotensin-converting enzyme (ACE) may modify some aspects of the clinical picture of Pompe disease. Although high interindividual differences are commonly observed, serum levels of ACE are rather stable when measured repeatedly in the same subject. At least one half of the interindividual differences are under genetic control, due to the insertion/deletion polymorphism. The insertion/deletion polymorphism has been implicated in many different clinical problems (hypertension, atherosclerosis, coronary heart disease, and stroke), including muscle performance. $^{8}$ The $\mathrm{D}$ allele has been associated with better power performance, whereas the I allele would be associated with improved endurance. ${ }^{9}$ The rationale for this study is thus based on the observations that this polymorphism influences fiber-type distribution and muscle properties ${ }^{10,11}$ and affects the phenotype of another GSD, namely McArdle disease. ${ }^{12,13}$

\section{METHODS}

\section{Patients}

Thirty-eight patients (20 men) affected by late-onset Pompe disease, including three sib pairs, were enrolled in the study. This study was approved by the Local Ethical Committees of the involved centers; all patients gave written consent to participation. The diagnosis was suggested by the clinical picture and confirmed by mutation analysis in all but six patients. In these patients, in addition to the $-32-13 \mathrm{~T}>\mathrm{G}$ mutation, a reduced level of acid alpha-glucosidase activity was demonstrated in lymphocytes and/or muscle biopsy. Main clinical and demographic data, and the results of mutation analysis, are shown in Table 1 . The majority (30 of 38) of patients were on a high-protein diet (consisting in 20$25 \%$ proteins) and were instructed to perform physical activity. Compliance to these interventions, however, was highly variable among patients and with time; no major differences in distribution or compliance was observed in the groups defined by the ACE genotype. Only Patient 36 was on low-dose ACE inhibitors (ramipril $2.5 \mathrm{mg} /$ day).

The duration of the follow-up of the patients varied from 1 to 11 years (median, 7 years). Disease severity was assessed using the modified Walton scale. ${ }^{14}$ The neurologists who collected the clinical data (S.R., B.B., F.G.) were unaware of ACE polymorphism status.

\section{Molecular analysis}

Blood samples for DNA analysis were obtained after informed consent. Mutation analysis was performed as reported, ${ }^{15}$ 
Table 1 Mutations identified in 38 patients with late-onset of Pompe disease

\begin{tabular}{|c|c|c|c|c|c|}
\hline Patient & Allele 1 & Allele 2 & $\mathrm{ACE}$ & Age, gender & Walton score \\
\hline 1 & $-32-13 \mathrm{~T}>\mathrm{G}$ & $?$ & ID & $38, \mathrm{~F}$ & 2 \\
\hline 2 & $-32-13 \mathrm{~T}>\mathrm{G}$ & $?$ & $\mathrm{DD}$ & $58, \mathrm{~F}$ & 7 \\
\hline 3 & $-32-13 \mathrm{~T}>\mathrm{G}$ & $?$ & $\mathrm{DD}$ & $14, \mathrm{M}$ & 1 \\
\hline 4 & $-32-13 \mathrm{~T}>\mathrm{G}$ & $?$ & ID & $74, \mathrm{~F}$ & 6 \\
\hline 5 & $-32-13 \mathrm{~T}>\mathrm{G}$ & $?$ & $\mathrm{DD}$ & $38, \mathrm{M}$ & 6 \\
\hline 6 & $-32-13 \mathrm{~T}>\mathrm{G}$ & $?$ & ID & $12, \mathrm{M}$ & 2 \\
\hline 7 & $-32-13 \mathrm{~T}>\mathrm{G}$ & $1561 \mathrm{G}>\mathrm{A}$ & II & $59, \mathrm{~F}$ & 6 \\
\hline 8 & $-32-13 \mathrm{~T}>\mathrm{G}$ & 2298_2301delCTTCinsAAAGTA & ID & $56, \mathrm{M}$ & 3 \\
\hline 9 & $2014 \mathrm{C}>\mathrm{T}$ & $1064 \mathrm{~T}>\mathrm{C}$ & $\mathrm{DD}$ & $35, \mathrm{~F}$ & 6 \\
\hline 10 & $-32-13 \mathrm{~T}>\mathrm{G}$ & $1927 \mathrm{G}>\mathrm{A}$ & DD & $28, \mathrm{~F}$ & 4 \\
\hline 11 & $-32-13 \mathrm{~T}>\mathrm{G}$ & $1331 \mathrm{C}>\mathrm{G}$ & II & $18, \mathrm{M}$ & 1 \\
\hline 12 & $-32-13 \mathrm{~T}>\mathrm{G}$ & $1465 \mathrm{G}>\mathrm{A}$ & ID & $53, \mathrm{M}$ & 6 \\
\hline 13 & $-32-13 \mathrm{~T}>\mathrm{G}$ & $1465 \mathrm{G}>\mathrm{A}$ & $\mathrm{DD}$ & $43, \mathrm{M}$ & 3.5 \\
\hline 14 & $-32-13 \mathrm{~T}>\mathrm{G}$ & 1776del & ID & $58, \mathrm{M}$ & 5 \\
\hline 15 & $-32-13 \mathrm{~T}>\mathrm{G}$ & 1833_1839del;1846G > T; 1847_1848insT & ID & $35, \mathrm{~F}$ & 2 \\
\hline 16 & $-32-13 \mathrm{~T}>\mathrm{G}$ & $1836 \mathrm{C}>\mathrm{G}$ & $\mathrm{DD}$ & $38, \mathrm{~F}$ & 2 \\
\hline 17 & $-32-13 \mathrm{~T}>\mathrm{G}$ & $2104 \mathrm{C}>\mathrm{T}$ & $\mathrm{DD}$ & $31, \mathrm{M}$ & 2 \\
\hline 18 & $-32-13 \mathrm{~T}>\mathrm{G}$ & $2237 \mathrm{G}>\mathrm{A}$ & ID & $59, \mathrm{~F}$ & 6 \\
\hline 19 & $-32-13 \mathrm{~T}>\mathrm{G}$ & $2237 \mathrm{G}>\mathrm{A}$ & ID & $62, \mathrm{~F}$ & 7 \\
\hline 20 & $-32-13 \mathrm{~T}>\mathrm{G}$ & $2237 \mathrm{G}>\mathrm{A}$ & II & $40, \mathrm{M}$ & 1 \\
\hline 21 & $-32-13 \mathrm{~T}>\mathrm{G}$ & $2237 \mathrm{G}>\mathrm{A}$ & ID & $79, \mathrm{M}$ & 5 \\
\hline 22 & $-32-13 \mathrm{~T}>\mathrm{G}$ & $2237 \mathrm{G}>\mathrm{A}$ & ID & $48, \mathrm{M}$ & 4 \\
\hline 23 & $-32-13 \mathrm{~T}>\mathrm{G}$ & $2237 \mathrm{G}>\mathrm{A}$ & ID & $8, \mathrm{~F}$ & 1 \\
\hline 24 & $-32-13 \mathrm{~T}>\mathrm{G}$ & 2530-41delEx18 & ID & $58, \mathrm{~F}$ & 3 \\
\hline 25 & $-32-13 \mathrm{~T}>\mathrm{G}$ & 2646_2646+1delTG & ID & $47, \mathrm{M}$ & 3 \\
\hline 26 & $-32-13 \mathrm{~T}>\mathrm{G}$ & $525 \mathrm{delT}$ & $\mathrm{DD}$ & $36, \mathrm{M}$ & 7 \\
\hline 27 & $-32-13 \mathrm{~T}>\mathrm{G}$ & 525 delT & ID & $60, \mathrm{~F}$ & 3.5 \\
\hline 28 & $-32-13 \mathrm{~T}>\mathrm{G}$ & $525 \mathrm{delT}$ & ID & $51, \mathrm{M}$ & 2 \\
\hline 29 & $-32-13 \mathrm{~T}>\mathrm{G}$ & $525 \mathrm{delT}$ & $\mathrm{DD}$ & $46, \mathrm{~F}$ & 3 \\
\hline 30 & $-32-13 \mathrm{~T}>\mathrm{G}$ & $525 \mathrm{delT}$ & II & $49, \mathrm{M}$ & 6 \\
\hline 31 & $-32-13 \mathrm{~T}>\mathrm{G}$ & 525 delT & ID & $70, \mathrm{M}$ & 0 \\
\hline 32 & $1645 \mathrm{G}>\mathrm{C}$ & $692+1 G>C$ & $\mathrm{DD}$ & $12, \mathrm{~F}$ & 1 \\
\hline 33 & $-32-13 \mathrm{~T}>\mathrm{G}$ & $692+1 \mathrm{G}>\mathrm{C}$ & $\mathrm{DD}$ & $36, \mathrm{~F}$ & 2 \\
\hline 34 & $-32-13 \mathrm{~T}>\mathrm{G}$ & $925 \mathrm{G}>\mathrm{A}$ & $\mathrm{DD}$ & $55, \mathrm{~F}$ & 6 \\
\hline 35 & $-32-13 \mathrm{~T}>\mathrm{G}$ & 2219_2220delTG & ID & $22, \mathrm{M}$ & 0 \\
\hline 36 & $-32-13 \mathrm{~T}>\mathrm{G}$ & IVS+1076-1G-C & II & $83, \mathrm{M}$ & 6 \\
\hline 37 & $-32-13 \mathrm{~T}>\mathrm{G}$ & IVS + 1076-1G-C & II & $73, \mathrm{M}$ & 3.5 \\
\hline 38 & $-32-13 \mathrm{~T}>\mathrm{G}$ & $1655 \mathrm{~T}>\mathrm{C}$ & ID & $13, \mathrm{~F}$ & 0 \\
\hline
\end{tabular}


and ACE polymorphisms were determined as described by Lindpaintner et al. ${ }^{16}$

\section{Analysis of clinical features}

We compared the distribution of the ACE genotypes in relation to the following parameters: sex; age; age of onset of the disease (i.e., patients were invariably asked about the onset of motor/respiratory difficulties in running/climbing stairs and/or rising from a chair); disease duration (from the above symptoms onset to actual age); serum creatine kinase (CK) levels, both at the time of diagnosis and at the latest follow-up (in view of the retrospective nature of our study, the information about CK levels at diagnosis was unavailable in 3 of 38 cases); severity of the disease, using the modified Walton scale ${ }^{14}$; presence of scoliosis; symptoms of fatigue, as assessed by the Fatigue Severity Scale ${ }^{17}$; presence of muscle pain, as assessed by a Visual Analogic Scale (only pain at rest/during exercise was considered, whereas pain related to muscle cramps/fatigue was excluded); body mass index (BMI); 6-minute walking test (6MWT); signs of fatigue during the 6MWT, defined as oxygen desaturation $\geq 5 \%$ or heart rate increase $\geq 20 \%$; vital capacity, expressed both as percentage and in liters; and range of disease manifestations, with annotation of prevalence of respiratory versus muscular involvement or lack of a prevailing pattern.

To evaluate disease progression rate, we also considered the genotype distribution in relation to age and stage of disease. For the analysis, the II, ID, and DD genotypes were evaluated with each other by multiple pairwise comparisons (DD versus ID versus II). As the parameters of interest were significantly different in the DD group (Table 2), comparison of this latter with the II + ID groups was also considered.

Statistical analysis was performed using the SPSS statistical package version 17.0 (SPSS, Chicago, IL). Continuous variables were compared according to the genotype group by analysis of variance (ANOVA) and multiple posthoc comparisons, or Kruskal-Wallis test, depending on the distribution of the variable. This latter was assessed by the Kolmogorov-Smirnov test. Categorical variables were compared using the $\chi^{2}$ test. Two-tailed values of $P<0.05$ were considered as statistically significant.

\section{RESULTS}

Details about the clinical picture are included in Table 1. Cases 35 and 38 were diagnosed serendipitously, after the finding of consistent, unexplained hyperCKemia. This prompted a muscle biopsy, and the evidence of glycogen-filled vacuoles led to mutation analysis. Because these patients were found to be still fully asymptomatic at the latest follow-up, they were not included in the computations of disease parameters. We included three sib pairs in the study, as well as (Table 1): Cases 36 of 37 were ACE concordant (II) and clinically similar; Cases 27 of 31 were ACE concordant (ID) and clinically very dissimilar; Cases 28 of 29 were ACE

Table 2 Demographic and disease features according to ACE genotypes

\begin{tabular}{|c|c|c|c|c|c|c|c|}
\hline & \multirow[b]{2}{*}{ Total } & \multicolumn{3}{|c|}{ ACE genotype } & \multicolumn{2}{|c|}{ DD vs. ID vs. II $^{a}$} & \multirow[b]{2}{*}{ DD vs. II + ID $\left(\chi^{2} / t\right), P$} \\
\hline & & II & ID & $\mathrm{DD}$ & $\chi^{2 b} / F$ & $P$ & \\
\hline$N(\%)$ & 38 & $6(15.8)$ & $18(47.4)$ & $14(36.8)$ & - & - & - \\
\hline Age (yr) & $44.6 \pm 19.8$ & $53.6 \pm 23.4$ & $48.2 \pm 21.5$ & $36.3 \pm 12.8$ & 2.32 & 0.113 & 0.086 \\
\hline Gender, M:F & $20: 18$ & $5: 1$ & $10: 8$ & $5: 9$ & $3.93^{b}$ & 0.140 & 0.98 \\
\hline Onset age (yr) & $28.7 \pm 15.7$ & $39.5 \pm 17.2$ & $31.1 \pm 17.1$ & $21.5 \pm 9.9$ & 3.5 & 0.041 & 0.013 \\
\hline Disease duration & $17.5 \pm 10.9$ & $15 \pm 9.6$ & $21.1 \pm 13.2$ & $14.5 \pm 7.2$ & 1.6 & 0.21 & \\
\hline Age at diagnosis (yr) & $34.8 \pm 20.6$ & $43 \pm 24.4$ & $39.7 \pm 21.7$ & $24.2 \pm 12.8$ & 5.87 & 0.053 & 0.025 \\
\hline CK at onset & $767 \pm 488$ & $638.9 \pm 225.7$ & $575 \pm 363$ & $1049 \pm 582$ & 4.23 & 0.024 & 0.019 \\
\hline Walton score (median) & 3 & 4.75 & 3 & 3.25 & $0.034^{b}$ & 0.852 & 0.56 \\
\hline Scoliosis $(\%)$ & $11 / 36(30.5)$ & 33 & 23 & 54 & $3.36^{b}$ & 0.182 & 0.09 \\
\hline Muscle pain & $16 / 36(44 \%)$ & 0 & $43 \%$ & $64 \%$ & $12.31^{b}$ & 0.014 & 0.012 \\
\hline FSS score & $49.3 \pm 10.8$ & $56.6 \pm 7.7$ & $50.6 \pm 6.9$ & $42 \pm 17.3$ & 1.2 & 0.34 & 0.71 \\
\hline BMI & $22.9 \pm 5.1$ & $24 \pm 5$ & $23.4 \pm 4.5$ & $21.7 \pm 6.1$ & 0.52 & 0.59 & 0.37 \\
\hline MWT & $250 \pm 199$ & $207.3 \pm 212.1$ & $283.9 \pm 207.3$ & $231.8 \pm 191.2$ & 0.41 & 0.76 & 0.71 \\
\hline Fatigue 6-MWT (\%) & $12 / 30(40)$ & 50 & 52 & 32 & $0.25^{b}$ & 0.87 & 0.25 \\
\hline $\begin{array}{l}\text { Range of manifestations: } \\
\text { resp/musc/no prev }\end{array}$ & $6 / 13 / 12$ & $1 / 3 / 2$ & $4 / 4 / 8$ & $4 / 6 / 2$ & $3.99^{b}$ & 0.407 & 0.22 \\
\hline $\mathrm{VC} \%$ & $-33 \pm 30.7$ & $-33 \pm 32$ & $-32 \pm 33$ & $-34 \pm 30$ & 0.08 & 0.99 & 0.84 \\
\hline $\mathrm{VC}$ & $2.4 \pm 1.2$ & $2.7 \pm 1.5$ & $2.2 \pm 1.2$ & $2.4 \pm 1.2$ & 0.30 & 0.74 & 0.74 \\
\hline
\end{tabular}

${ }^{a}$ In the posthoc analysis, the group significantly different from the others is shown in bold

${ }^{b}$ Analyses on categorical variables, that were performed by $\chi^{2}$

FSS, Fatigue Severity Scale; BMI, body mass index; MWT, minute walking test; ACE, angiotensin-converting enzyme; CK, creatine kinase; VC, vital capacity; $\mathrm{resp} / \mathrm{musc} / \mathrm{no} \mathrm{prev}$, mainly respiratory/mainly muscle weakness/no prevalent pattern. 


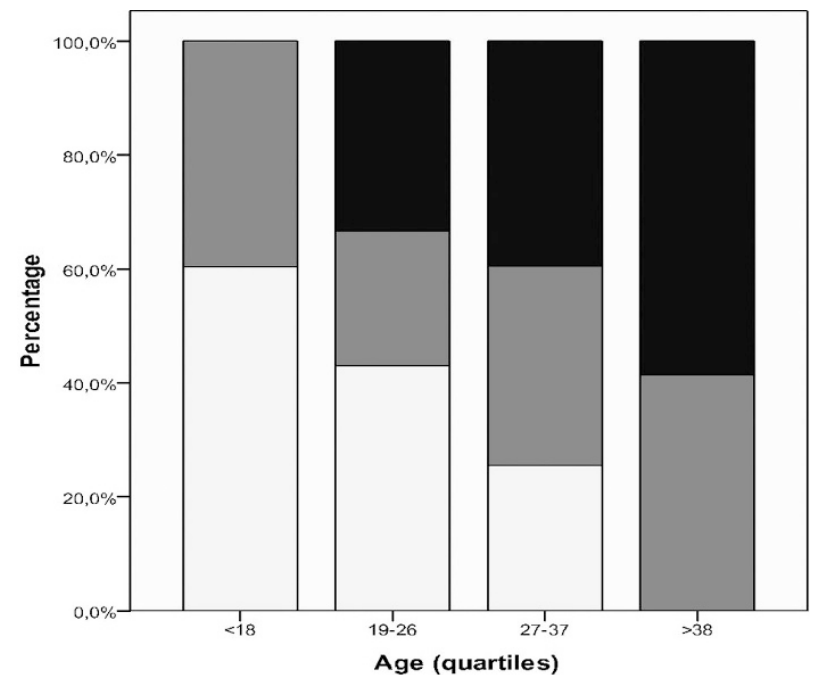

Fig. 1. Distribution of ACE polymorphism according to age of onset. The patients are divided in quartiles, according to onset age. The II polymorphism is absent in the first quartile, whereas the DD polymorphism is absent in the last quartile of age of onset $\left(\chi^{2}=6.32, P=0.012\right)$.

discordant (ID and DD, respectively) with an earlier and more severe clinical presentation for Case 29.

The $-32-13 \mathrm{~T}>\mathrm{G}$ mutation was found in 36 of 38 cases. The second mutation was the $2237 \mathrm{G}>\mathrm{A}$ and $525 \mathrm{delT}$ in six cases for each mutation. All the mutations found in our cases have been already reported in the Pompe disease mutation database except for 2298_2301delCTTCinsAAAGTA (Patient 8) and 1331C $>\mathrm{G}$ (Patient 11). Mutations [-32-13T $>\mathrm{G}]$ and $[1645 \mathrm{G}<\mathrm{C}]$ are reported in the International Database as mild, mutation $[2014 \mathrm{C}<\mathrm{T}]$ is reported as intermediate, whereas the remaining are severe mutations.

The frequency of the D allele of ACE was 0.592 in our cohort of 38 cases, and the distribution of the II/ID/DD genotypes was in agreement with the Hardy-Weinberg equilibrium. The II genotype was found in 6 cases and the DD genotype in 13 .

A significant difference in the distribution of the genotypes (F $=3.5, P=0.041$, ANOVA) was observed for the age of onset, the DD genotype being associated with an earlier onset of the disease. The significance was found to increase when the DD genotype was compared with the II + ID genotypes $(\mathrm{F}=$ 3.044, $P=0.013, t$ test).

The DD polymorphism also showed a significant correlation with higher serum $\mathrm{CK}$ levels at diagnosis $(\mathrm{F}=4.23, P=0.024$, ANOVA $)$ and with the presence of muscle pain $\left(\chi^{2}=12.31\right.$, $P=0.014)$.

As for BMI, a significant difference was found only when females alone were considered $\left(P=0.029, \chi^{2}\right.$, data not shown): the DD genotype was associated with a lower BMI.

The influence of genotype on the age of onset is also illustrated in Figure 1 where the II genotype is lacking in the lowest age quartile, and, in contrast, the DD genotype is lacking in the higher age quartile $\left(\chi^{2}=6.32, P=0.012\right)$.

As shown in Figure 2, the patients were also grouped into three categories: mild (Walton score: $0-2$ ), moderate (Walton score: $2.5-4$ ), and severe (Walton score: 5-7) involvement. When age and genotypes are considered, DD genotype is found to be significantly associated with the most severely affected

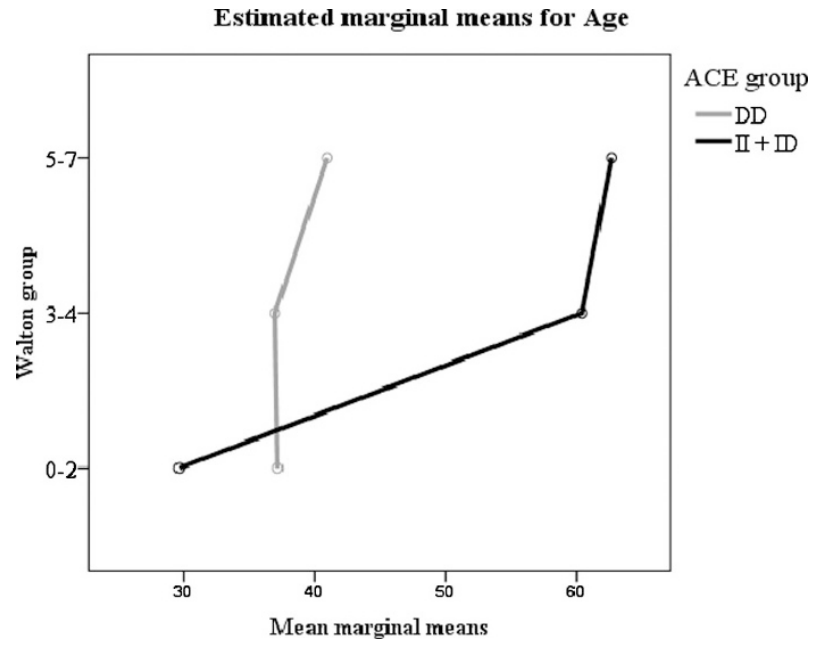

Fig. 2. Distribution of ACE polymorphism according to age and stage of disease. The DD polymorphism is compared with the II + ID polymorphism. Walton score is grouped as mild (Walton 0-2), moderate (Walton 2.5-4), and severe (Walton 5-7). In patients with the II + ID genotype, there is a linear correlation between age and worsening of motor dysfunction. In contrast, the DD genotype shows a more severe disease course in which disease severity seems unpredictable on the basis of age, and there is no correlation between age and stage of disease (univariate ANOVA: dependent variable: Age; fixed factors: ACE polymorphism and Walton groups; effect of interaction: $F=3.88, P=0.035)$.

group (ANOVA test for interaction, $\mathrm{F}=3.79, P=0.037$ ), with a nonlinear relationship between age and motor dysfunction.

All the other above-mentioned comparisons gave no significant results (Table 2).

\section{DISCUSSION}

The phenotypical heterogeneity observed among patients suffering from Pompe disease, even when carrying the same mutation, as well as the variability reported within families, support the view that modifying (genetic) factors are present and are relevant to define the final clinical presentation and disease course. ${ }^{5,6}$ Even in the mouse model, different phenotypes are observed among knock out mice with different backgrounds. ${ }^{7}$ To identify possible genetic factors that can modify the clinical presentation of patients with Pompe disease, we investigated the ACE insertion/deletion polymorphism in a population of 38 juvenile/adult cases.

The rationale for studying ACE genotypes was based on published evidence of the effect of this polymorphism on the physiological properties of the muscle. ${ }^{8-11}$

In addition, recent reports suggest the ACE genotypes are relevant in the clinical presentation of a different GSD also, namely McArdle disease. In particular, the number of $\mathrm{D}$ alleles was found to correlate with a more severe phenotype ${ }^{12,13}$ although this observation was not confirmed in a subsequent, smaller study. ${ }^{18}$ In this study, we observed a significant correlation between the DD genotype and age of onset (Table 2 and Fig. 1). It is certainly difficult to properly assess the age of onset of a slowly progressive disorder in which an early muscular dysfunction can be easily overlooked, and the clinical diagnosis 
is often delayed. However, in our study, the age of onset was defined by a neurologist blind to the genetic data, and fully trained in the management of patients with Pompe disease, who carefully evaluated the first appearance of muscular impairment. We defined "age of onset" as related to the first time when the patient noticed a difficulty in running or climbing stairs. We thought that this parameter could reflect a more objective evaluation, rather than the mere recognition of the time of onset of muscle pain or fatigue. The latter information is indeed far more subjective, and also possibly influenced by patient's self-perception and by other occasional clinical disturbances.

The higher (although not significant) incidence of the DD genotype in patients presenting with scoliosis fits with this observation because it is well known that generally the presence of scoliosis in a muscle disease reflects the existence of a muscular dysfunction already during prepubertal growth. ${ }^{19}$

The DD genotype is associated with a higher ACE activity. This, in turn, results in lower half-life of bradykinin and increased production of angiotensin II, with vasoconstriction. Thus, the physiological impact of the ACE genotype may take place by reduced endothelium-dependent vasodilatation and decreased substrate delivery to the working muscles. ${ }^{8,20}$ This point might be of particular relevance in a disorder primarily due to the inability of muscle to use stored glycogen, so that the muscle energy supply becomes fully dependent on circulating glucose.

The D allele is also associated with an increase in type II fibers $^{11}$ that are less rich in mitochondria and thus more sensitive to oxidative stress. ${ }^{21}$

In Pompe disease, the specific relevance of an increased number of type II fibers in muscles may be also related to autophagy. The consequences of the lysosomal glycogen accumulation are indeed strikingly different in type I and II muscle fibers. Only type II fibers contain large regions of autophagic buildups that span the entire length of the fibers, as demonstrated in mice. ${ }^{22,23}$ In our opinion, the full set of the biological data reported is a reliable explanation of the fact that DD genotype is associated with an earlier onset of the disease. The interpretation of the significantly higher CK levels in the DD genotype must be taken with caution: it may be the expression of a more severe muscle damage, but we should also consider that, first, high variability in CK levels is commonly observed, and, second, that the data on CK levels at the onset of the disease were collected retrospectively, and thus did not allow us to take into account possible influencing factors.

We also observed a significant association of the DD genotype with the presence of muscular pain. The occurrence of muscular pain in patient with Pompe disease has not been specifically addressed yet, and no pathophysiologic explanation has been provided. ${ }^{24}$ The study of the nature of pain in patient with Pompe disease is of course beyond the aim of this work, but we hypothesize that a role for microvessel damage and impaired clearance of yet unidentified toxic agents derived from muscle catabolism may be claimed. The importance of ACE for microvessel integrity is underlined by previous studies on diabetic nephropathy. ${ }^{8}$

In addition to the age of onset, disease progression significantly impacts the prognosis of patient with Pompe disease. To evaluate disease progression, we considered the combination of two parameters: age and Walton scale. The latter is a wellrecognized instrument for assessing the severity and progression of neuromuscular disorders. By combining disease stage (as measured by Walton scale) with age, we obtained an estimate of the rate of disease progression. Once an effect of the DD genotype was demonstrated, we compared DD and II + ID genotypes in relation to age and Walton score groups. The DD genotype proved to be significantly associated with a more severe Walton score, at any age, suggesting an effect on disease progression also. In contrast, when considered independently of age, the DD genotype was not associated with a worse Walton score, or with any of the other clinical parameters reflecting disease severity. The absence of a correlation with the disease stage alone is at variance with previous observations in McArdle disease. ${ }^{12,13}$ Such discrepancy can be explained by the different course of the disease (nonprogressive, with normal life span, in McArdle ${ }^{25}$ ) and by the different type of scale (the former -10/11-being largely based on subjective parameters) used to define the disease stage. However, the lack of association is not at all surprising, as the number of modifying factors is likely to be wide, and clinical aspects such as oxygen saturation at $6 \mathrm{MWT}$ or BMI are likely to be influenced by genes controlling completely different metabolic pathways.

In our sample, we identified two subgroups of six patients each, carrying the same mutations (i.e. $-32-13 \mathrm{~T}>\mathrm{G} / 2237 \mathrm{G}>\mathrm{A}$ and $-32-13 \mathrm{~T}>\mathrm{G} / 525 \mathrm{delT}$ ). However, age and Walton score were found to be highly variable and thus were not different within groups, in line with the notion that phenotypical heterogeneity may occur despite identical mutations. Because of the small size, no clear difference could be found between the two subgroups with regard to other variables.

The number and size of families with more than one patient were also too small to draw any reliable conclusion. However, we wish to point out that in the sib pair discordant for the ACE genotype, an earlier and more severe clinical picture was again associated to the DD genotype.

In conclusion, according to our findings, ACE genotype can represent one of the factors responsible for the wide clinical variability observed in Pompe disease. It would appear that carriers of the DD genotype will experience an earlier onset of the clinical symptoms and will more rapidly reach a stage of severe motor dysfunction.

Although these findings need to be confirmed in larger groups of cases, we believe that accurate evaluation of the mechanism of muscle damage and regeneration will provide the rationale to investigate other genes, whose variations, either alone or with an addictive effect on ACE genotypes, will further clarify the clinical heterogeneity of Pompe disease.

\section{REFERENCES}

1. van der Ploeg AT, Reuser AJ. Pompe's disease. Lancet 2008;372:13421353.

2. Kroos M, Pomponio R, van Vliet L, et al; GAA Database Consortium Update of the Pompe disease mutation database with 107 sequence variants and a format for severity rating. Hum Mutat 2008;29:E13-E26.

3. Kroos M, Pomponio R, Hagemans M, et al. Broad spectrum of Pompe disease in patients with the same c.-32-13T- $>$ G haplotype. Neurology 2007;68:110-115.

4. Van der Beek NA, Hagemans ML, Reuser AJ, et al. Rate of disease progression during long-term follow-up of patients with late-onset Pompe disease. Neuromuscul Disord 2009;19:113-117.

5. Smith W, Sullivan-Saarela J, Li J, et al. Sibling phenotype concordance in classical infantile Pompe disease. Am J Med Genet 2007;143:2493-2501.

6. Ausems M, ten Berg K, Beemer F, Wokke JH. Phenotypic expression of late-onset glycogen storage disease type II: identification of asymptomatic adults through family studies and review of reported families. Neuromuscul Disord 2000;10:467-471.

7. Raben N, Nagaraju K, Lee E, Kessler P, et al. Targeted disruption of the acid alpha-glucosidase gene in mice causes an illness with critical features of both infantile and adult human glycogen storage disease type II. J Biol Chem 1998;273:19086-19092.

8. Sayed-Tabatabaei FA, Oostra BA, Isaacs A, van Duijn CM, Witteman JC. ACE polymorphisms. Circ Res 2006;98:1123-1133.

9. Wagner H, Thaller S, Dahse R, Sust M. Biomechanical muscle properties and angiotensin-converting enzyme gene polymorphism: a model-based 
study. Eur J Appl Physiol 2006;98:507-515.

10. Williams A, Rayson M, Jubb M, et al. The ACE gene and muscle performance. Nature 2000;403:614

11. Zhang B, Tanaka H, Shono N, et al. The I allele of the angiotensinconverting enzyme gene is associated with an increased percentage of slow-twitch type I fibers in human skeletal muscle. Clin Genet 2003;63: 139-144.

12. Rubio JC, Gomez-Gallego F, Santiago C, et al. Genotype modulators of clinical severity in McArdle disease. Neurosci Lett 2007;422:217-222.

13. Martinuzzi A, Sartori E, Fanin M, et al. Phenotype modulators in myophosphorylase deficiency. Ann Neurol 2003;53:497-502.

14. Slonim A, Bulone L, Goldberg T, et al. Modification of the natural history of adult-onset acid maltase deficiency by nutrition and exercise therapy. Muscle Nerve 2007;35:70-77.

15. Montalvo A, Bembi B, Donnarumma M, et al. Mutation profile of the GAA gene in 40 Italian patients with late onset glycogen storage disease type II. Hum Mutat 2006;27:999-1006.

16. Lindpaintner K, Pfeffer MA, Kreutz R, et al. A prospective evaluation of an angiotensin-converting-enzyme gene polymorphism and the risk of ischemic heart disease. $N$ Engl J Med 1995;332:706-711.

17. Hagemans ML, van Schie SP, Janssens AC, van Doorn PA, Reuser AJ, van der Ploeg AT. Fatigue: an important feature of late-onset Pompe disease. J Neurol 2007;254:941-945.
18. Rommel O, Kley RA, Dekomien G, Epplen JT, Vorgerd M, Hasenbring M Muscle pain in myophosphorylase deficiency (McArdle's disease): the role of gender, genotype, and pain-related coping. Pain 2006;124:295-304

19. Yamashita T, Kanaya K, Kawaguchi S, Murakami T, Yokogushi K. Prediction of progression of spinal deformity in Duchenne muscular dystrophy: a preliminary report. Spine 2001;26:E223-E226.

20. Woods DR, Humphries SE, Montgomery HE. The ACE I/D polymorphism and human physical performance. Trends Endocrinol Metab 2000;11:416420 .

21. Gosker HR, van Mameren H, van Dijk PJ, et al. Skeletal muscle fibre-type shifting and metabolic profile in patients with chronic obstructive pulmonary disease. Eur Respir $J$ 2002;19:617-625.

22. Fukuda T, Ewan L, Bauer M, et al. Dysfunction of endocytic and autophagic pathways in a lysosomal storage disease. Ann Neurol 2006;59:700-708.

23. Raben N, Takikita S, Pittis MG, et al. Deconstructing Pompe disease by analyzing single muscle fibers: to see a world in a grain of sand. Autophagy 2007;3:546-552.

24. Hagemans M, Winkel L, Van Doorn P, et al. Clinical manifestation and natural course of late-onset Pompe's disease in 54 Dutch patients. Brain 2005;128:671-677.

25. Kishnani P, Koeberl D, Chen Y-T. Glycogen storage diseases. In: Scriver C, Beaudet A, Sly W, Valle D, editors. The metabolic and molecular bases of inherited disease. New York, NY: McGraw-Hill, 2001:1537-1551. 